\title{
Perception of radiography lecturers towards the proposed doctor of radiography program
}

\author{
Beatrice Ukamaka Maduka ${ }^{1 *} \mathbb{D}$, Anthony Chukwuka Ugwu² and Bakky Ngozi Adirika ${ }^{3}$
}

\begin{abstract}
Background: Radiography as a profession has undergone significant changes in recent times with the introduction of new imaging modalities, increase in the ranges of radiological investigations, and a diversification in the role of radiographers. As a result of these, there is a need to step up the radiography program to meet up with these changes. This study aims at ascertaining the perception of radiography lecturers in Nigeria towards the proposed doctor of radiography program. A cross-sectional study of radiography lecturers in Nigeria was conducted from February to July 2020. Subjects were recruited through a convenient sampling technique. Validated questionnaires were sent online to all the lecturers. The questionnaire contained 32 questions divided into 3 sections. Section A captured the demographic data of the lecturers. Section B captured information on the ability of the doctor of radiography program to produce graduates with a broad orientation in all specialties of radiography. Section C elicited information on the ability of the doctor of radiography program to produce high-quality radiographers.

Results: A total of 62 lecturers comprising 51 males (82.3\%) and 11 females (17.7\%) participated in the study. The grand mean of all the items in sections B and C were 3.03 and 3.25 respectively which show that the respondents are confident that the proposed program will produce high-quality and versatile radiographers.
\end{abstract}

Conclusion: The lecturers showed a positive perception towards the doctor of radiography program. Hence, they strongly believe that the proposed program will produce more versatile radiographers than the bachelor's program.

Keywords: Radiography, Perception, Doctor, Curriculum

\section{Background}

Since the introduction of $\mathrm{x}$-ray imaging so many years ago, radiography has evolved rapidly into a more complicated practice with a great deal of responsibilities and duties [1]. Radiography has thus, undergone many transformations with a diversification in the role of radiographers. Over the years, there has been a significant change in radiography education and practice [2]. Radiography education in Nigeria started in the 1940s in the South-West region via a diploma training program [3]. The diploma training program was anchored by the

\footnotetext{
*Correspondence: beatrice.maduka@unn.edu.ng

'Department of Medical Radiography and Radiological Sciences, University of Nigeria, Enugu Campus, Enugu, Nigeria

Full list of author information is available at the end of the article
}

Federal School of Radiography Lagos which was then the only school that produced radiographers in the country. The duration of training for the program was four years [4]. Graduates from the Federal School of Radiography, Lagos were awarded Diploma College of Radiographers (DCR), London in the 1970s while as from 1993 the graduates were awarded Diploma Institute of Radiography (DIR), Nigeria.

In 1982 and 1983, the University of Calabar and University of Nigeria, Nsukka, started the 5-year Bachelor of Science (BSc) program in radiography respectively [3]. Twenty-two years after the start of the BSc program, there were calls to stop the diploma program. Hence, the program was finally stopped in 2004 [4]. The radiography profession finally settled for full-fledged first 
degree in university as a minimum qualification for practice [3]. Currently, there are many imaging modalities within the purview of radiographers as contained in the Radiographers Registration Board of Nigeria (RRBN) Act [5]. The modalities include Conventional Radiography, Ultrasonography, Computed Tomography, Magnetic Resonance Imaging, Mammography, Radiation Therapy, and Nuclear Medicine [3], and there is a need for radiography students to master skills in these areas. In the 5 -year Bachelor of Science program run currently by Nigerian universities, conventional radiography receives a great emphasis at the expense of the new imaging modalities.

The doctor of radiography (D-Rad) program started in Pakistan in 2013. The program is equal to professional and clinical masters' degree like doctor of Pharmacy (Pharm-D) [6]. There are marked differences between the doctor of radiography program and the bachelor's program. In terms of duration, the doctor of radiography program is expected to last for 6 years or twelve semesters while the bachelor's program lasts for 5 years or ten semesters. This is in order to keep in pace academically with other health professional groups like Pharmacy and Medical Rehabilitation. In terms of curriculum, the doctor of radiography program will have a more robust and comprehensive curriculum which will cover all imaging modalities in radiography unlike the bachelor's program that concentrates on conventional x-ray imaging. The doctor of radiography program will introduce new courses like advanced ultrasound, advanced computed tomography, advanced magnetic resonance imaging, advanced nuclear medicine, radiotherapy treatment setup and patient management, echocardiography, basics of Doppler ultrasound, forensic radiography, and film reporting. This will help to produce radiographers who will be very versatile in all aspects of radiography and beyond and also have an in-depth knowledge of the basic and emerging trends in the field of imaging [7]. The doctor of radiography program and the bachelor's program are two separate programs; they are not complementary to each other. As at the moment, the bachelor of radiography program is currently run in the country of study. But there is an intention to replace the bachelor of radiography program with the doctor of radiography program as obtained in sister professions.

The expanded curriculum of the doctor of radiography program in line with modern technology worldwide will help to train radiographers who can adapt to practice in a variety of clinical settings without regional update training and examinations. Hence, there is the need for the 6-year doctor of radiography program to replace the 5 -year Bachelor of Science Radiography program in
Nigeria. The objective of this study is to ascertain the perception of radiography lecturers towards the proposed doctor of radiography program.

\section{Methods}

This study adopted a cross-sectional survey. Participation was voluntary and the respondents were assured in writing that their personal details would be treated as confidential. Ethical approval for the study was obtained. This study was carried out in all the universities of Nigeria offering radiography as a course of study. The study population comprised radiography lecturers $(n=$ 62) employed in both public and private universities in Nigeria. Participation was voluntary and there were no exclusion criteria.

Validated questionnaire was used in the collection of data. The questionnaire was designed to elicit quantitative and qualitative information. It contained 32 questions which were divided into 3 sections. Section A captured the demographic data of the lecturers: sex, age, rank, years of lecturing, institution, and highest academic qualification. Section B captured information on the perceived versatility of graduates of the program in all specialties of radiography. Section $C$ elicited information on the perceived quality of radiographers that will be produced by the program. The measuring tool ascertained the perception of the radiography lecturers towards the doctor of radiography program. This required the respondents to rate their level of perception on a 4point Likert scale: $1=$ strongly disagree (SD) to $4=$ strongly agree (SA).

The questionnaire was validated by two senior lecturers in radiography department and a senior lecturer in education foundations unit. A pilot study was conducted among some radiography lecturers in the University of Nigeria Enugu Campus and its reliability computed using Cronbach's alpha which gave a coefficient of 0.93 and 0.96 for sections $B$ and $C$ respectively. This indicates a good level of consistency and reliability. The questionnaire was designed using the survey monkey tool and a link created. The questionnaire was sent online to all the 70 radiography lecturers in Nigeria. Weekly reminders were sent to the lecturers by the researchers for a period of 2 months. As the lecturers filled the questionnaires and submitted online, the researchers got alerts of their responses via an e-mail address created and specially designated for the study. Sixty-two lecturers accurately filled the questionnaire after a period of two months resulting to a percentage response rate of $89 \%$.

Statistical analysis was done using Statistical Package for Social Sciences (Windows Version 23; SPSS Inc, Chicago, USA). Both descriptive and inferential statistics were carried out. Frequencies and percentages were used 
to describe the demographic characteristics of the respondents. Mean and standard deviation were used to ascertain the perception of the lecturers on the ability of the doctor of radiography program to produce versatile and high-quality radiographers. A mean of 2.50 and above was accepted while any with a mean of 2.49 and below was rejected. Independent sample $t$ test was used to test the hypothesis. Statistical significance was considered at $p<0.05$.

\section{Results}

Table 1 summarizes the demographic characteristics of the respondents. A total of 62 lecturers, 51 males $(82.3 \%)$ and 11 females (17.7\%) participated in the study. Of the 62 lecturers that took part in the study, 4 (6.5\%) were readers and professors, 11 (17.7\%) were senior lecturers, 28(45.2\%) were lecturers II and I while 19(30.6\%) were assistant lecturers. Age group 21-35 years had the highest frequency $(53.2 \%)$. Majority of the respondents (50.0\%) had Masters Degree in radiography as their highest academic qualification. The lecturing experience of the majority of the respondents was between 1 and 10 years $(77.4 \%)$.

Table 2 shows the perception of the lecturers on the versatility of graduates of the doctor of radiography program. The grand mean of all the items in section B was 3.03 (a grand mean of $>2.50$ shows an agreement while a grand mean of $<2.50$ shows a disagreement). This shows that the respondents agree that the doctor of radiography program will produce graduates that are versatile in all the specialties of radiography.

Table 3 shows the perception of the lecturers on the quality of radiographers that will be produced by the doctor of radiography program. The grand mean of all the items in section $C$ was 3.25. (A grand mean of $>2.50$ shows an agreement while a grand mean of $<2.50$ shows a disagreement). It shows the respondents agree that the doctor of radiography program would be able to produce high-quality radiographers that can rise to the highest levels in public and private sectors.

Table 4 shows independent sample $t$ test of the two categories of lecturers on perceived versatility of graduates of the doctor of radiography program. The $t$ test shows the $p$ value to be 0.056 (which is greater than $0.05)$. This shows that there is no significant difference between the two categories of lecturers on the perceived versatility of graduates of the doctor of radiography program.

Table 5 shows independent sample $t$ test of the two categories of lecturers on perceived quality of graduates of the doctor of radiography program. The $t$ test shows the $p$ value to be 0.063 (which is greater than 0.05 ). This shows that there is no significant difference between the two categories of lecturers on the perceived quality of
Table 1 Demographic data of the respondents

\begin{tabular}{|c|c|c|}
\hline Variables & Frequency & Percentage \\
\hline \multicolumn{3}{|l|}{ Gender } \\
\hline Female & 11 & 17.7 \\
\hline Male & 51 & 82.3 \\
\hline Total & 62 & 100.0 \\
\hline \multicolumn{3}{|l|}{ Age (years) } \\
\hline $21-35$ & 33 & 53.2 \\
\hline $36-50$ & 18 & 29.0 \\
\hline$>50$ & 11 & 17.7 \\
\hline Total & 62 & 100.0 \\
\hline \multicolumn{3}{|l|}{ Rank } \\
\hline Assist. Lecturers & 19 & 30.6 \\
\hline Lecturers II and I & 28 & 45.2 \\
\hline Senior Lecturer & 11 & 17.7 \\
\hline Reader and Professor & 4 & 6.5 \\
\hline Total & 62 & 100.0 \\
\hline \multicolumn{3}{|c|}{ Lecturing experience (years) } \\
\hline $1-10$ & 48 & 77.4 \\
\hline $11-20$ & 10 & 16.1 \\
\hline $21-30$ & 3 & 4.8 \\
\hline Above 30 & 1 & 1.6 \\
\hline Total & 62 & 100.0 \\
\hline \multicolumn{3}{|c|}{ Highest educational attainment } \\
\hline B.Sc. & 10 & 16.2 \\
\hline M.Sc. & 31 & 50.0 \\
\hline Ph.D. & 21 & 33.9 \\
\hline Total & 62 & 100.0 \\
\hline \multicolumn{3}{|l|}{ Institution } \\
\hline$A B U$ & 4 & 6.5 \\
\hline BUK & 10 & 16.1 \\
\hline UDUS & 6 & 9.6 \\
\hline UNICAL & 12 & 19.4 \\
\hline UNILAG & 6 & 9.6 \\
\hline UNIMAID & 12 & 19.4 \\
\hline NAU & 12 & 19.4 \\
\hline Total & 62 & 100.0 \\
\hline
\end{tabular}

professionals that will be produced by the doctor of radiography program.

\section{Discussion}

A total of 62 lecturers comprising 51 males (82.3\%) and 11 females (17.7\%) took part in the study. The grand mean for increased versatility and knowledge was 3.03 and is a pointer to the fact that the lecturers perceive that the doctor of radiography program will lead to the production of radiographers with a broad orientation in 
Table 2 Perception on versatility of radiographers that will be produced by the program

\begin{tabular}{|c|c|c|c|c|c|c|c|c|}
\hline Items on versatility & SA & A & D & SD & $\mathrm{U}$ & Mean & S. D. & Decision \\
\hline Increased knowledge & $28(54.2)$ & $24(38.7)$ & $1(1.6)$ & $2(3.2)$ & $7(11.3)$ & 3.03 & 1.280 & A \\
\hline Increased versatility & $25(40.3)$ & $26(41.9)$ & $3(4.8)$ & $2(3.2)$ & $6(9.7)$ & 3.00 & 1.215 & A \\
\hline Coverage of more content & $39(62.9)$ & $18(29.0)$ & $1(1.6)$ & $2(3.2)$ & $2(3.2)$ & 3.45 & 0.935 & A \\
\hline Greater exposure to ideas & $25(40.3)$ & $28(45.2)$ & $2(3.2)$ & $2(3.2)$ & $5(8.1)$ & 3.06 & 1.143 & A \\
\hline Better opportunity to research deeply & $25(40.3)$ & $28(45.2)$ & $4(6.5)$ & $2(3.2)$ & $3(4.8)$ & 3.13 & 1.016 & A \\
\hline Ability to focus on their interest areas & $23(37.1)$ & $29(46.8)$ & $1(1.6)$ & $1(1.6)$ & $8(12.9)$ & 2.94 & 1.279 & A \\
\hline Effective discussion of issues in their areas of interest & $26(41.9)$ & $26(41.9)$ & $1(1.6)$ & $1(1.6)$ & $8(12.9)$ & 2.98 & 1.299 & A \\
\hline Ability to address problem areas in radiography & $21(33.9)$ & $22(35.5)$ & $6(9.7)$ & $1(1.6)$ & $12(19.4)$ & 2.63 & 1.462 & A \\
\hline Ability to compete favorably in the Nigerian labor market & $28(45.2)$ & $23(37.1)$ & $5(8.1)$ & $1(1.6)$ & $5(8.1)$ & 3.10 & 1.155 & A \\
\hline Ability to meet up with the demands of the modern health sector. & $26(41.9)$ & $22(35.5)$ & $3(4.8)$ & $1(1.6)$ & $10(16.1)$ & 2.90 & 1.375 & A \\
\hline Ability to compete favorably with their contemporaries internationally & $20(32.3)$ & $29(46.8)$ & $7(11.3)$ & $1(1.6)$ & $5(8.1)$ & 2.94 & 1.114 & A \\
\hline In-depth scientific background to enrich Radiography practice & $26(41.9)$ & $25(40.3)$ & $1(1.6)$ & $1(1.6)$ & $9(14.5)$ & 2.94 & 1.353 & A \\
\hline Production of radiographers with higher professional competence & $28(45.2)$ & $22(35.5)$ & $6(9.7)$ & $1(1.6)$ & $5(8.1)$ & 3.08 & 1.164 & A \\
\hline Production of radiographers with sufficient management ability & $13(21.0)$ & $30(48.4)$ & $6(9.7)$ & $0(0.0)$ & $13(21.0)$ & 2.48 & 1.400 & $\mathrm{D}$ \\
\hline Possession of basic entrepreneurial skills & $7(11.3)$ & $29(46.8)$ & $14(22.6)$ & $0(0.0)$ & $12(19.4)$ & 2.31 & 1.275 & D \\
\hline Production of radiographers that can report medical images effectively & $14(22.6)$ & $21(33.9)$ & $7(11.3)$ & $3(4.8)$ & $17(27.4)$ & 2.19 & 1.545 & $\mathrm{D}$ \\
\hline Ability to coordinate the activities of other radiographers. & $16(25.8)$ & $26(41.9)$ & $10(16.1)$ & $1(1.6)$ & $9(14.5)$ & 2.63 & 1.296 & A \\
\hline Grand mean & & & & & & 3.03 & 1.280 & A \\
\hline
\end{tabular}

$A$ agree/accepted, $D$ disagree/not accepted

all specialties of radiography. From this study, the graduates of the doctor of radiography program will exhibit increased knowledge and broad orientation in all specialties than the graduates of the basic bachelor's program. This is one of the objectives that an ideal doctor of radiography program should be able to achieve. This is similar to the findings of Lehto et al. [8] who carried out a study in undergraduate program in palliative medicine at Tampere and examined the students at the end. It was discovered that an increase in the number of hours of palliative medicine provided to the medical students led to an increase in knowledge of the students.
Milin et al. [9] carried out a similar study on the impact of a mental health program on knowledge among students in Canada. The changes in mental health knowledge were measured using pre-test and post-test questionnaires and it was discovered that there was a significant change in knowledge scores over time with scores increasing from pre-test to post-test. The findings of this study are also in line with the work of Fiese et al. [10] who developed a program for undergraduate students on the causes and consequences of obesity. Students were administered online surveys prior to the beginning of the class and at the end of the semester.

Table 3 Perception on quality of radiographers that will be produced by the program

\begin{tabular}{|c|c|c|c|c|c|c|c|c|}
\hline Items on quality & SA & A & D & SD & $\mathrm{U}$ & Mean & S. D. & $\overline{\text { Decision }}$ \\
\hline Competence in three imaging modalities. & $27(43.5)$ & $26(41.9)$ & $3(4.8)$ & $0(0.0)$ & $6(9.7)$ & 3.10 & 1.169 & A \\
\hline Ability to rise to the highest level in public service. & $35(56.5)$ & $23(37.1)$ & $1(1.6)$ & $2(3.2)$ & $1(1.6)$ & 3.44 & 0.822 & A \\
\hline The radiographers can contribute to policy formulation. & $28(45.2)$ & $29(46.8)$ & $4(6.5)$ & $1(1.6)$ & $4(6.5)$ & 3.26 & 0.957 & A \\
\hline The radiographers can enhance policy implementation. & $27(43.5)$ & $26(41.9)$ & $4(6.5)$ & $1(1.6)$ & $4(6.5)$ & 3.15 & 1.069 & A \\
\hline Ability to command respect like their medical counterparts & $23(37.1)$ & $29(46.8)$ & $3(4.8)$ & $1(1.6)$ & $6(9.7)$ & 3.00 & 1.173 & A \\
\hline Ability to perform effectively in hospital diagnostic services & $32(51.6)$ & $28(45.2)$ & $1(1.6)$ & $1(1.6)$ & $0(0.0)$ & 3.47 & 0.620 & A \\
\hline Ability to perform effectively in public health services & $26(41.9)$ & $31(50.0)$ & $1(1.6)$ & $1(1.6)$ & $3(4.8)$ & 3.23 & 0.948 & A \\
\hline The radiographers can function independently in the discharge of duties & $24(38.7)$ & $30(48.4)$ & $2(3.2)$ & $1(1.6)$ & $5(8.1)$ & 3.08 & 1.106 & A \\
\hline Collaboration with other members of the health team & $33(53.2)$ & $27(43.5)$ & $1(1.6)$ & $1(1.6)$ & $0(0.0)$ & 3.48 & 0.620 & A \\
\hline Grand mean & & & & & & 3.25 & 0.18 & A \\
\hline
\end{tabular}


Table 4 Independent sample $t$ test of the two categories of lecturers on perceived versatility of graduates of the program

\begin{tabular}{lllllll}
\hline Ranks & $\boldsymbol{N}$ & Mean & S. D. & $\boldsymbol{t}$ value & $\boldsymbol{p}$ value & Decision \\
\hline Lower cadre lecturers & 47 & 2.9908 & 0.82 & 1.952 & 0.056 & NS \\
Higher cadre lecturers & 15 & 2.4941 & 0.98 & & & \\
Total & $\mathbf{6 2}$ & & & & & \\
\hline
\end{tabular}

NS not significant

The students demonstrated a significant increase in knowledge on obesity and as such, the program was recommended to be adopted in the undergraduate setting. Similarly, Aboumatar et al. [11] developed a patient safety program for medical students and evaluated its impact on medical students' safety knowledge. A prepost assessment of students' safety knowledge was conducted and the result showed an increased knowledge among the students. The result of this study disagreed with the study by Newton [12] on New Welsh program which involved seeking the opinion of teachers in the country on the new program about to be introduced. Most of the teachers expressed the fear that the program may drastically reduce the students' level of knowledge and such constitute a problem to the students, teachers, and the society at large.

For the training of high-quality radiographers the grand mean, gotten was 3.25 and it is a pointer to the fact that the lecturers perceive the doctor of radiography program will lead to the production of high-quality radiographers that can rise to the highest levels in both public and private sectors so as to better contribute towards policy formulation and implementation in the health sector. This is because in the comity of health professionals, radiography has major areas of specialization which are conventional radiography, diagnostic ultrasound, computed tomography, magnetic resonance imaging, nuclear medicine, mammography, and radiation therapy, and these areas exist as definitive departments in so many health institutions globally. The present study is in line with a study carried out by Mumbo and Kinaro [13] on the assessment of the relevance of program development in health training institutions. According to the researchers, strengthening of health training institutions to increase the quality of health workers produced is very important and ensures access to universal quality health coverage. This entails design and constant reviews of the curriculum of these programs to meet the needs of the modern health sector. Similarly, Abdulaziz [1] carried out a study on radiography education and training and found out that a highquality program for radiographers is necessary to produce competent radiographers for both diagnostic and therapeutic working environment. Hence, there is a need to review radiography education and training so as to fulfill the needs of the modern health sector.

Independent sample $t$ test of the two categories of lecturers showed that there is no significant difference in the mean of the different categories of lecturers on perceived knowledge and versatility of graduates of the doctor of radiography program. This can be explained by the fact that the program will introduce new areas and courses that are relevant to the radiography profession. So, the graduates will definitely be more versatile in all aspects of radiography than the graduates of the bachelor's program. Also, another independent sample t-test shows that there was no significant difference in the mean of the two categories of lecturers on the perceived quality of professions that will be produced by the doctor of radiography program. This implies that both the lower cadre (Lecturers I, Lecturers II, and Assistant Lecturers) and higher cadre lecturers (Professors, Readers, and Senior Lecturers) are confident that the doctor of radiography program will lead to the production of high-quality radiographers that can rise to the highest levels in both public and private sectors.

The doctor of radiography program is a welcome development for radiography lecturers in Nigeria. Since the program will be able to produce more versatile and higher quality radiographers than the basic bachelor's program, it is recommended to serve as a replacement for the basic bachelor's program.

\section{Limitations of the study}

The sample size used for the study was small. This is because there are very few radiography lecturers in Nigeria. Also, there were no documented studies carried out in the past on the doctor of radiography program. This affected the effective discussion of findings as there were no strongly related works in radiography to compare and contrast the findings of this study with.

Table $\mathbf{5}$ Independent sample $t$ test of the two categories of lecturers on perceived quality of radiographers that will be produced by the program

\begin{tabular}{|c|c|c|c|c|c|c|}
\hline Rank & $N$ & Mean & S. D. & $t$ value & $p$ value & Decision \\
\hline Lower cadre lecturers & 47 & 3.3357 & 0.63215 & 1.896 & 0.063 & NS \\
\hline Higher cadre lecturers & 15 & 2.9556 & 0.80431 & & & \\
\hline Total & 62 & & & & & \\
\hline
\end{tabular}

NS not significant 


\section{Conclusion}

The lecturers showed a positive perception towards the proposed doctor of radiography program. The study found out that the doctor of radiography program will produce radiographers with a broader orientation in all specialties of radiography than the bachelor's program. Also, the program will produce high-quality radiographers that can rise to the highest levels in the public and private sectors.

\section{Abbreviations}

DCR: Diploma College of Radiographers; DIR: Diploma Institute of Radiography; B.Sc: Bachelor of Science; RRBN: Radiographers Registration Board of Nigeria; D-Rad: Doctor of Radiography; Pharm-D: Doctor of Pharmacy; SD: Strongly disagree; D: Disagree; A: Agree; SA: Strongly agree

\section{Supplementary Information}

The online version contains supplementary material available at https://doi. org/10.1186/s43055-021-00488-z.

Additional file 1: Section A. Demographic characteristics. Section B. Versatility in all the specialties of radiography. Section $\mathbf{C}$. Training of high quality radiographers.

\section{Acknowledgements}

Not applicable.

\section{Authors' contributions}

All authors have read and approved the manuscript. Each author participated sufficiently in this submission and the roles of the authors are: $\mathrm{MBU}$ was the main researcher, drafted the manuscript, responsible for data capturing, presentation of results, and interpretation of results. UAC gave recommendations regarding the literature review. ABN provided critical comments on the research work.

\section{Funding}

Not applicable.

\section{Availability of data and materials}

The datasets used and/or analyzed during the current study are available from the corresponding author on reasonable request.

\section{Declarations}

\section{Ethics approval and consent to participate}

Ethical approval for the study was obtained from the Human Research and Ethics Committee of Nnamdi Azikiwe University, Nnewi Campus. There was no Ethics committee reference number in the ethical approval letter given to the researchers. Written informed consent to participate in the study was obtained from all the lecturers.

\section{Consent for publication}

Not applicable.

\section{Competing interests}

The authors declare that they have no competing interests.

\section{Author details}

'Department of Medical Radiography and Radiological Sciences, University of Nigeria, Enugu Campus, Enugu, Nigeria. ${ }^{2}$ Department of Radiography and Radiological Sciences, Nnamdi Azikiwe University, Nnewi Campus, Nnewi, Nigeria. ${ }^{3}$ Department of Educational Foundations, Nnamdi Azikwe University, Awka, Nigeria.
Received: 21 January 2021 Accepted: 4 April 2021

Published online: 15 April 2021

\section{References}

1. Abudulaziz SA (2012) Radiography education and training in Saudi Arabia. Open J Radiol 2(4):134-140

2. Pratt S, Adams C (2013) How to create a degree course in radiography: a recipe. Radiography 9(4):317-322

3. Adejoh T (2019) An inquest into the quests and conquests of the Radiography profession in Nigeria. J Radiogr Radiat Sci 33(1):1-38

4. Ejidike EC. Radiography in Nigeria: an insight; 2017. www.idcsig.org. Accessed 12 June 2020.

5. Radiographers registration act of Nigeria decree 42 chapter R1 1987; pp 117. Accessed 2 July 2020

6. Medical Imaging Doctor. University of Lahore. 2019. www.medicalkidunya. com. Accessed 30 June 2020

7. Sloane C, Miller PK (2017) Informing radiography curriculum development: the views of UK radiology service managers concerning the fitness for purposes of recent diagnostic radiography graduates. Radiography 23(1):10-23

8. Lehto JT, Hakkarainen K, Kellokumpu-Lehtinen P (2017) Undergraduate curriculum in palliative medicine at Tampere University increases student's knowledge. BMC Palliat Care 16(13):182-198

9. Milin R, Kutcher S, Lewis SP, Walker S, Wei Y, Ferrill N, Armstrong M (2016) Impact of a mental health curriculum on knowledge and stigma among high school students: a randomized controlled trial. J Am Acad Child Adolesc Psychiatry 55(5):383-391

10. Fiese BH, Hammons A, Koester B, Garcia GL, Parker L, Teegarden D (2019) Trans disciplinary obesity prevention research sciences curriculum increases knowledge about complex causes and consequences of obesity for undergraduate students. Front Public Health 7(1):232-238

11. Aboumatar HJ, Thompson D, Wu A, Dawson P, Colbert J, Marsteller J, Kent P, Lubomski LH, Paine L, Pronovost P (2012) Development and evaluation of a 3-day patient safety curriculum to advance knowledge, self-efficacy and system thinking. BMJ Qual Saf 21(5):416-422

12. Newton N. New Welsh curriculum may make education more holistic but students might miss out on subject knowledge. https://theconversation. com. Accessed 25 June 2020.

13. Mumbo HM, Kinaro JW (2015) Assessment of quality and relevance of curricula development in health training institutions: a case study of Kenya. Hum Resour Health 13(1):67-77

\section{Publisher's Note}

Springer Nature remains neutral with regard to jurisdictional claims in published maps and institutional affiliations.

\section{Submit your manuscript to a SpringerOpen ${ }^{\circ}$ journal and benefit from:}

- Convenient online submission

- Rigorous peer review

- Open access: articles freely available online

High visibility within the field

- Retaining the copyright to your article

Submit your next manuscript at $>$ springeropen.com 